\title{
A TUTELA COLETIVA DO PATRIMÔNIO CULTURAL
}

COLLECTIVE PROTECTION OF THE CULTURAL HERITAGE

LA TUTELA COLECTIVA DEL PATRIMONIO CULTURAL

Carlos Alberto Lunelli ${ }^{1}$

Jeferson Dytz Marin²

1 Carlos Alberto Lunelli: Doutor em Direito - Universidade do Vale do Rio dos Sinos (RS). Mestre em Direto - Universidade do Vale do Rio dos Sinos (RS). Professor no Mestrado em Direito da Universidade de Caxias do Sul - UCS (RS). Advogado. E-mail: calunelli@gmail. com. CPF: 374.019.040-04. Endereço: Rua 13 de Maio, 581, sala 402, Centro, Bento Gonçalves - RS - CEP: 95700-000. Telefones: (54) 2521-4244 ou (54) 9973-4709.

2 Jeferson Marin: Doutor em Direito - Universidade do Vale do Rio dos Sinos (RS). Mestre em Direito - Universidade de Santa Cruz do Sul (RS). Professor do Programa de Mestrado em Direito da Universidade de Caxias do Sul - USC (RS). Advogado. E-mail: jdmarin@ucs. br. CPF: 787.022.400-68. Endereço: Rua 13 de Maio, 581, sala 402, Centro, Bento Gonçalves - RS - CEP: 95700-00. Telefones: (54) 2521-4244 ou (54) 9925-6810. 
Resumo: A proteção do patrimônio cultural é tarefa árdua numa sociedade com as características do Brasil, de formação peculiar, decorrente do processo colonial. Percebe-se a necessidade de que a propriedade desempenhe a sua função social, eis que o processo de urbanização trouxe novas compreensões à sociedade brasileira. Assim, no sentido de garantir a efetividade da proteção do patrimônio cultural, houve intensa produção legislativa. Com a Constituição Federal de 1988, inaugurou-se uma nova ordem jurídica, com maior preocupação com a proteção ambiental. Todavia, ainda se faz necessária a atuação do Judiciário, a fim de garantir o cumprimento da legislação protetiva do bem ambiental.

Palavras-chave: Patrimônio cultural. Ações coletivas. Judicialização.

Abstract: The protection of cultural heritage is an arduous task in a society like that of Brazil, which has its own peculiar formation, due to the colonial process. There is a need for property to perform its social function, since the process of urbanization has brought new insights into Brazilian society. Thus, to ensure the effectiveness of protection of the cultural heritage, there was an intense legislative production. With the Federal Constitution of 1988, a new legal order was inaugurated, with greater concern for environmental protection. However, there is still a need for judiciary actions to ensure compliance with the legislation and the protection of the environment.

Keywords: Cultural heritage. Collective actions. Judicialization.

Resumen: La protección del patrimonio cultural es una tarea árdua en una sociedad con las características de Brasil, de formación peculiar, consecuencia del proceso colonial. Se observa la necesidad de que la propiedad desempeñe su función social, ya que el proceso de urbanización trajo nuevas comprensiones a la sociedad brasileña. Así, con el propósito de garantizar la efectividad de la protección del patrimonio cultural, hubo una intensa producción legislativa. Con la Constitución Federal de 1988 se in- 
auguró un nuevo orden jurídico, con mayor preocupación por la protección ambiental. Sin embargo, todavía se hace necesaria la actuación del Poder Judicial a fin de garantizar el cumplimiento de la legislación protectiva del bien ambiental.

Palabras clave: Patrimonio cultural. Acciones colectivas. Judicialización.

\section{INTRODUÇÃO}

ideia de cooperação social entre os indivíduos assinala algumas formas
de restrições às suas liberdades individuais, já que a autonomia de
vontade deve ser delimitada de acordo com o meio social em que o cidadão está inserido. O mesmo se diz em relação ao Direito de Propriedade, que tem assinalado importantes restrições ao uso, devendo cumprir uma função social. Assim, como o cidadão já não pode decidir se trabalha ou não trabalha, uma vez que a sociedade espera dele um resultado, a propriedade também não está ao alvitre de seu dono, no sentido de ser utilizada ou não, já que está inserida em um meio social e tem uma função a cumprir.

O tema que se propõe é o estudo da evolução da proteção patrimonial no Brasil, a partir do Direito de Propriedade, analisado sob o aspecto de sua função social. Ainda, busca-se perceber os mecanismos disponibilizados ao administrador público para proteção do patrimônio cultural, bem como a compreensão que o Judiciário tem acerca da matéria.

Percebe-se a relevância que a tutela ambiental ganhou no cenário jurídico brasileiro, em especial depois da Constituição Federal de 1988, momento a partir do qual passou a ser considerada garantia fundamental da pessoa. Todavia, apenas a existência da tutela constitucional não é suficiente se não se verificarem mecanismos de controle efetivos.

Assim, a adoção de uma postura judicial ativa apresenta-se como uma das possibilidades de proteção do patrimônio cultural, ainda mais numa sociedade como 
a brasileira, que apresenta características peculiares e, por sua formação, muitas vezes registra a tendência de esquivar-se da preservação do patrimônio histórico.

A proteção do patrimônio cultural, no caso brasileiro, depende da atuação do Poder Judiciário, chamado a exercer papel efetivo na tutela desse bem, que tem amparo na Constituição Federal.

\section{A FORMAÇÃO CULTURAL BRASILEIRA E O PROCESSO DE} URBANIZAÇÃO

Quando se trata de compreender a questão que envolve a proteção do patrimônio no Brasil, é necessário perceber, em primeiro lugar, os fundamentos da formação cultural da sociedade brasileira e do próprio processo de urbanização.

A sociedade brasileira é uma sociedade multicultural, que se inicia a partir do processo de colonização europeia sob forte influência portuguesa. A escravidão teve um papel decisivo na formação cultural brasileira, tendo perdurado até o final do Século XIX. Com o fim da escravidão, acentua-se o processo de imigração europeia, o que contribuiu decisivamente para a formação de uma cultura que tem inúmeras variantes. É possível afirmar, sem receio de errar, que a sociedade brasileira encerra culturas diferentes que, ainda, produziram um resultado curioso.

Assim, a cultura brasileira ora se representa pela miscigenação de diferentes culturas, ora aparece segmentada, em resquícios, por vezes bem evidentes, das formações culturais originais.

Afora esse aspecto, a vocação colonialista em que se formou a sociedade brasileira produziu consequências que até hoje são bem fortes na formação cultural. O colonizado nutre o desejo interno de assemelhar-se ao colonizador. O que provém da Coroa é o desejo. O que sai da Colônia é abjeto. Assim, essa formação foi determinante para a criação de um processo de urbanização peculiar, também movido pela disposição de escapar da origem colonial.

É possível afirmar, assim, que o processo de urbanização, no Brasil, acontece como um movimento que representa a própria libertação da condição colonial e da condição de explorado. Por isso, essa urbanização, de modo quase natural, 
procura sintomaticamente escapar das amarras coloniais e que representam o resgate do passado. Por esse motivo, certamente, justifica-se a dificuldade que se apresenta quando se trata de garantir a preservação do patrimônio, notadamente o patrimônio material arquitetônico.

\section{URBANIZAÇÃO E PROTEÇÃO DO PATRIMÔNIO CULTURAL}

NO BRASIL

No início, a vida em sociedade teve por propósito a garantia da força, já que unidos os cidadãos detinham melhores possibilidades de enfrentar seus inimigos e de se abastecerem. Assim, a cidade passou a ser concebida com uma necessidade humana, como já reconhecia Aristóteles 3 :

[...] a cidade faz parte das coisas da natureza, que o homem é naturalmente um animal político, destinado a viver em sociedade, e aquele que, por instinto, e não porque qualquer circunstância o inibe, deixa de fazer parte de uma cidade, é um vil ou superior ao homem. Tal indivíduo merece, como disse Homero, a censura cruel de ser sem família, sem leis, sem lar. Porque ele é ávido de combates, e, de combates, e, como as aves de rapina, incapaz de se submeter a qualquer obediência.

Por certo que à época do início das cidades, se fazia a necessidade de cumprimento de algumas normas para convivência pacífica entre os membros que nela estavam inseridos, numa espécie de associação em busca de um interesse maior. Na contemporaneidade, essas normas expressam-se pela garantia de sustentabilidade das cidades, numa concepção de que a cidade haverá de ser pensada numa dimensão que permita o desenvolvimento dos indivíduos, com condições de vida digna para as presentes e futuras gerações. É o que atualmente, no caso brasileiro, é compreendido como o "projeto de cidade".

A ideia de um "projeto de cidade" engloba muito mais do que a legislação vigente por suas leis ou diretrizes de crescimento municipal. Seus propósitos estão concebidos "em termos funcionais e racionais, mas com uma preocupação

3 ARISTOTELES. A Política. Coleção Grandes Obras do Pensamento Universal. Trad.: Nestor Silveira Chaves. São Paulo: Editora Escala. 2003. p. 15. 
básica humana, isto é, com os valores espirituais, visando o homem no contexto urbano e a melhoria de suas condições de vida" ${ }^{4 \prime}$.

Send o o homem comum o seu principal destinatário, o urbanismo, além do bemestar, deve sopesar uma série de interesses gerais das comunidades envolvidas, conservando, preservando e mantendo valores e edificações históricas que nelas estão inseridas e que compõem a realidade social que foi anteriormente objeto da legislação. Ao promover o equilíbrio dos mais variados interesses sociais, as decisões ou alternativas devem garantir o direito de propriedade, avaliando-se, dentre tantos outros aspectos, a necessidade de permanência da paz social.

Esses desideratos, todavia, não têm sido facilmente aplicados no caso brasileiro, cuja especulação imobiliária apresenta-se como inimiga capital da preservação do patrimônio cultural.

A ideia de propriedade em muito acompanha os propósitos da economia. Os índices de construção ou de ocupação de determinada área refletem diretamente nos valores de mercado das propriedades. Deve-se sempre considerar que a economia tem ditado as regras de conservação do meio ambiente, e ao que tudo indica, o trata como uma das tantas variáveis do empreendimento, conforme ensina Michel Bachelet: "para a economia, a ecologia não passa de uma simples variável; os recursos naturais são outros tantos input integrados nos factores de produção"5. Para o ente estatal a definição parece se assemelhar, em muito, conforme se destaca:

A economia ambiental focaliza o papel da natureza como fornecedora de matéria-prima ou como receptora de materiais danosos. Dentro dessa redução, encontramos o sentido de meio ambiente. Assim, meio ambiente deixa-se conceituar como um espaço onde se encontram os recursos naturais, inclusive aqueles já reproduzidos (transformados) ou degenerados (poluídos), como no caso do meio ambiente urbano 6 .

4 MUKAI, Toshio. Direito urbano-ambiental brasileiro. 2. ed. Rev. e ampl. São Paulo: Ed. Dialética, 2002. p. 16.

5 BACHELET, Michel. Ingerência Ecológica: Direito Ambiental em questão. 4. ed. São Paulo: Editora Revista dos Tribunais, 2005. p. 162.

6 DERANI, Cristiane. Direito ambiental econômico. 3. ed. São Paulo: Ed. Saraiva, 2008. p. 51. 
Nos tempos atuais, não só a propriedade está assentada na ideia de função social, e sim o cidadão encontra a limitação de seus direitos com base em uma "atuação social" no meio em que está inserido, uma vez que as estruturas sociais que têm se moldado são muito mais complexas das que o Direito habitualmente pretendia tutelar. Trata-se, ainda, de perceber a sobreposição de propriedades no mesmo bem: uma, individual; outra, coletiva, expressa no patrimônio público.

Para Duguit, sobre as legislações da época, "os textos assinalam bem o que tem de absoluto, de exclusivo, a propriedade-direito nas concepções civilistas. É a manifestação por excelência da vontade humana, da soberania do indivíduo", mencionando, assim, que o direito de propriedade era absoluto.

Por força das novas normas ou mesmo das decisões reiteradas dos diversos tribunais dos países - alguns mais adiantados e outros menos nessa nova concepção social da propriedade -, tem-se assinalado que não se pode pensar em defender a propriedade ou os direitos do proprietário, senão quando produtora de utilidade. $\mathrm{E}$ assim como o cidadão, a propriedade está inserida no contexto social. Para Duguit:

La propiedad es una institución jurídica que se ha formado para responder a una necesidad económica, como por otra parte todas las necesidades jurídicas, y que evoluciona necesariamente con las necesidades económicas mismas.

Por esse novo modelo de propriedade que se define, alicerçada em limitações, tanto a propriedade quanto os indivíduos têm uma função social a cumprir e, nesse prisma, a propriedade e o trabalho devem ser utilizados como mecanismos de geração e distribuição de riqueza, e não como forma de enriquecer e centralizar o poder nas mãos dos empreendedores.

Não se pode inferir que o proprietário tenha perdido direitos em favor da coletividade, uma vez que suas garantias legais de proprietário podem ser utilizadas para reaver ou obstar a coisa de quem quer que seja. O que se verifica é que o uso da coisa está limitado ou proibido no caso da propriedade causar possíveis danos a terceiros ou a coletividade.

7 DUGUIT, León. Las Transformaciones del Derecho (público y privado). Buenos Aires: Editorial Helialista SRL, /s.d./p. 235. 
A especulação imobiliária causa danos à coletividade, uma vez que alimenta as estatísticas de deficit de habitação, dentre tantos outros problemas, projetando os mais pobres às áreas periféricas das cidades e contribuindo para a degradação social e ambiental:

[..] tal fenômeno é mais visível nas metrópoles - a ocupação de áreas de proteção ambiental situada nas faixas da pobreza e da miséria, gerando problemas amplamente conhecidos, tas como: córregos com lixo, enchentes decorrentes de entupimento, disseminação de doenças infecto contagiosas, epidemias, etc ${ }^{8}$.

Portanto, o que se observa é que a construção legislativa e a sua aplicação nos tribunais têm trazido ao bojo da sociedade importantes limitações do Direito de Propriedade. Todavia, decorre a necessidade de efetivação de tais normatizações ou dos comandos judiciais existentes. E considerando a inércia do administrador público diante da degradação do patrimônio cultural, surgiu o deslocamento da questão para o Judiciário como forma de equilibrar o uso sustentável e a ocupação ordenada das cidades.

\section{JUDICIALIZAÇÃO AMBIENTAL A PARTIR DA CONSTITUIÇÃO}

FEDERAL DE 1988

Com a Constituição Federal de 1988, o meio ambiente passou a ser assegurado constitucionalmente e equiparado a um direito fundamental da pessoa. A proteção do meio ambiente foi assumida como uma função pública e privada (conforme se extrai da norma do artigo 225, caput, da CF/88), cujo exercício se relaciona com os direitos fundamentais da qualidade de vida e utilização racional e sustentável dos recursos naturais.

Principalmente por meio das chamadas ações coletivas ${ }^{9}$, a tutela judicial do

8 COUTINHO, Ronaldo. Direito Ambiental das Cidades: Questões Teórico-Metodológicas. In: COUTINHO, Ronaldo; ROCCO, Rogério (Orgs.). Rio de Janeiro: D.P. \& A Editora, 2004. p. 55.

9 Conforme Anderson Furlan Freire da Silva (2002, p. 58): "pode se afirmar que tudo o que tem sido feito em matéria ambiental no Brasil hodierno, tanto preventiva quanto repressivamente, invariavelmente tem início em atos desencadeados pelo Ministério Público (CF/88, art. 129, III), pelas organizações não-governamentais, algumas fundações e uns poucos cidadãos ecologicamente conscientes. Atos que, de regra, tendem a passar pelo crivo do Poder Judiciário para que se tornem efetivos." 
meio ambiente ganhou evidência e relevância com o passar dos anos. É que o legislador ordinário, antes da promulgação da Constituição Federal de 1988, já observou a importância e o destaque que tal direito demandava para ser corretamente respeitado.

Dessa forma, as ações coletivas são a força instrumental para a realização processual da proteção do meio ambiente e, no Brasil, ganhou ainda mais evidência com a introdução no ordenamento jurídico da Lei da Ação Civil Pública, de acordo com a visão de Carlos Alberto Salles:

No Brasil, o grande marco representativo da introdução das ações coletivas no sistema brasileiro foi a promulgação da Lei 7.347/85, pela qual foi definitivamente introduzida no país a tutela judicial de interesses coletivos. Desde então, tem-se multiplicado o número de leis que direta ou indiretamente prevêem esse tipo de tutela, bem como tem aumentado a sua utilização.

Todavia, tem-se que superar urgentemente a distância entre a lei abstrata que consagra os mandamentos do Direito Ambiental e a realidade cotidiana, e para isso há a necessidade, além de um processo pedagógico de longo prazo, de uma ampla aliança, envolvendo todos os níveis de governo, entidades da sociedade civil e comunidade internacional.

Enquanto a consciência ambiental não completar o seu desenvolvimento e se disseminar no pensamento da população, enquanto o Estado de Direito Ambiental não se tornar uma realidade mundial - já que se vive em uma era cujo Estado passou a ser o guardião do lucro e da competitividade e as autoridades públicas em geral transformaram-se nos sacerdotes da ordem estabelecida -, vai cumprir ao Poder Judiciário desenvolver postura ativa dentro da moldura constitucional em que estiver inserto, o que quer dizer que os magistrados devem se libertar do princípio da inércia da jurisdição e galopar em busca do mais puro ativismo judicial, sempre com o desejo de preservar e/ou recuperar o meio ambiente.

A função do juiz para alcançar a proteção real ao meio ambiente é, de acordo com Plauto Faraco de Azevedo ${ }^{10}$, a de não admitir que os princípios constitucionais 10 AZEVEDO, Plauto Faraco de. Do Direito Ambiental - Reflexões sobre seu sentido e aplicação. In: Direito Ambiental em Evolução. FREITAS, Vladimir Passos de (Org.). Curitiba: 
se tornem parte de um discurso retórico-ornamental. Deve buscar efetivá-los, tornando-os "law in action", tendo em vista que o interesse que a norma protege é a própria vida. Não deve perturbá-lo a circunstância de que frequentemente se verá em face de situações em que existe verdadeiro conflito de interesses públicos, caso em que deverá avaliar os interesses em questão, optando pelo que melhor atenda os interesses da coletividade. Para bem decidir, carecerá não só de conhecimentos atualizados de cunho dogmáticos, visualizados em perspectiva crítica, como daqueles provenientes de outros ramos do conhecimento pertinentes ao caso.

Ou seja, com o crescimento em progressão geométrica dos casos em matéria ambiental que chegam à apreciação do Poder Judiciário, o "bom juiz" será aquele que melhor aplicar os conhecimentos da ciência jurídica ao caso concreto, mas sempre buscando a aplicação conjunta com matérias interdisciplinares correlatas, sob pena de decidir com a visão eminentemente biológica do meio ambiente, sem se preocupar com o anseio máximo descrito na Constituição Federal de 1988.

Ademais, a atividade do Poder Judiciário não se exaure na simples e comum subsunção da lei aos fatos, o que pode levar aos excessos e às surpresas da lógica formal aplicada ao direito. O processo hermenêutico sofre decisiva influência da ideia prévia que o intérprete tenha do direito, da vida e dos interesses em questão. Há que ter o juiz em conta a atuação das ideologias, já que, conforme Ruy Rosado de Aguiar Júnior ${ }^{11}$, ao julgar, o juiz sofre como qualquer pessoa a atuação de fatores múltiplos, de ordem emocional, psíquica, circunstancial, como também sente o efeito de suas convicções ideológicas, justamente por isso precisa ter lucidez suficiente que Ihe permita identificar, analisar e criticar as circunstâncias que o acometem, inclusive para se policiar, pois do contrário seria um ingênuo, influenciado por fatores que ele mesmo desconhece, mas que certamente existem e são eficazes.

A situação atual impõe o surgimento do juiz ideologicamente comprometido com a salvaguarda da Natureza. Ideologia em função da qual se preserva, entre outras coisas, a possibilidade de existência das gerações futuras. Esse 
comprometimento ideológico funda-se na assimilação do valor "meio ambiente" como invariável para o futuro, mas ameaçado em sua dimensão física pelo presente. Neste ponto, as concepções axiológica e normativa coincidem, como se pode ver pelo artigo 225 da Constituição Federal12. "A Constituição jurídica está condicionada pela realidade histórica. Ela não pode ser separada da realidade concreta de seu tempo"13.

Oatojudicial, principalmenteem matéria ambiental, insurgirá com umajudiciosa hermenêutica constitucional, em que sejam ponderados valores constitucionais que, em elevado número de situações, podem ocorrer entre o direito à propriedade privada e o direito de todos ao meio ambiente ecologicamente equilibrado.

Todavia, como ensina Luis Roberto Barroso ${ }^{14}$, essa ponderação não se deve desenvolver a partir do pressuposto da neutralidade e do seu complemento, a imparcialidade, pois esses pressupostos desafiam a realidade e não se aplicam, de jeito nenhum, em matéria ambiental, em que a proteção do meio ambiente se sobrepõe a quaisquer outros interesses, principalmente se forem privados. Aludido autor ${ }^{15}$, em lúcida observação, assim vaticina:

A neutralidade, entendida como um distanciamento absoluto da questão a ser apreciada, pressupõe um operador jurídico isento não somente das complexidades da subjetividade pessoal, mas também das influências sociais. Isto é: sem história, sem memória, sem desejos. Uma ficção.

Em conclusão acerca da interpretação da norma ambiental, Plauto Faraco de Azevedo ${ }^{16}$ diz que ela tem que pautar pela hermenêutica material, capaz de

12 SILVA, Anderson Furlan Freire da. Ativismo judicial em matéria ambiental. p. 58. In: Direito Ambiental em Evolução. FREITAS, Vladimir Passos de (Coord.). n.3, Curitiba: Juruá, 2002. p. 62-63.

13 HESSE, Konrad. A força normativa da Constituição. Porto Alegre: Sérgio Antônio Fabris Editor, 1991. p. 24.

14 BARROSO, Luís Roberto. Fundamentos teóricos e filosóficos do novo Direito Constitucional brasileiro (pós-modernidade, teoria crítica e pós-positivismo). Interesse Público, Sapucaia do Sul, RS: Notadez, v.3, n. 11, jul. 2001. p. 43-44.

15 BARROSO, Luís Roberto. Fundamentos teóricos e filosóficos do novo Direito Constitucional brasileiro (pós-modernidade, teoria crítica e pós-positivismo). Interesse Público, Sapucaia do Sul, RS: Notadez, v.3, n. 11, jul. 2001. p. 47.

16 AZEVEDO, Plauto Faraco de. Do Direito Ambiental - Reflexões sobre seu sentido e aplicação. In: Direito Ambiental em Evolução. FREITAS, Vladimir Passos de (Org.). Curitiba: Juruá, 1998. p. 295. 
evidenciar e acomodar os interesses em questão, desfazendo o jogo ideológico, de modo a prevalecer, em última instância, o direito fundamental da pessoa humana ao ambiente ecologicamente equilibrado, condição de sua vida histórico-cultural e de sua mesma sobrevivência.

\section{A PROTEÇÃO DO PATRIMÔNIO E DO AMBIENTE E A POSTURA DO PODER JUDICIÁRIO BRASILEIRO}

O Direito Processual está direcionado a objetivos instrumentais, voltando seus esforços à construção e ao funcionamento para mecanismos capazes de gerar a efetividade do ordenamento jurídico. Justamente por isso, quando não é alcançada a solução desejável por meio dos meios pré-processuais (negociação, mediação e arbitragem, por exemplo), o processo judicial é a alternativa natural para a solução da controvérsia.

Ocorre que os atores da marcha processual muitas vezes não se mostram perfeitamente adaptados ao tema ambiental, principalmente porque na academia, local apropriado para o aprimoramento da matéria, não se estuda e não se vê suficientemente a problemática acerca da indispensável proteção ao meio ambiente. Ou porque, no escólio de José Joaquim Gomes Canotilho ${ }^{17}$ :

Os juristas se debruçam hoje sobre o ambiente, deparando-se aí, no entanto, com enormes dificuldades: em parte provenientes da sua compreensível falta de preparação nos domínios da técnica e das ciências exactas e da inadequação dos instrumentos jurídicos tradicionais para resolver as questões ambientais na sua globalidade.

Quando a questão chega a juízo, sendo evidente que não foi resolvida administrativamente, as demandas ambientais reclamam atitudes positivas e que efetivamente se preocupem com a máxima proteção que se deseja, não se admitindo, por exemplo, desperdício de tempo na resolução do conflito, justamente porque muitos anos de desatenção ao meio ambiente tem que ser recuperados, ou melhor, amenizados para que as futuras gerações possam experimentar do mundo que o homem de hoje está, cada vez mais, destruindo. 17 CANOTILHO, José Joaquim Gomes. Introdução ao direito do ambiente. Lisboa: Universidade Aberta, 1998. p. 20. 
Assim, quando se trata de preservação do patrimônio público, são necessárias medidas enérgicas, que obriguem o cidadão a realizar essa proteção. A adoção de medidas coercitivas tem se verificado, nesse sentido, como uma das possibilidades de garantir a efetividade judicial ${ }^{18}$.

18 Nesse sentido, vale considerar o teor de decisão liminar, proferida pela Juíza de Direito da $3^{a}$ Vara Cível da Comarca de Bento Gonçalves (RS), no processo no 005/1.09.0002914-4, proposto pelo Município de Bento Gonçalves em face de Vinhos Salton S.A. Indústria e Comércio, objetivando a preservação do patrimônio histórico, decisão confirmada, no aspecto, pelo Tribunal de Justiça do Estado do Rio Grande do Sul: "Vistos. Recebo a inicial. Em face dos documentos acostados aos autos defiro o pedido liminar de embargo da obra que está sendo realizada pelo réu Vinhos Salton SA, no Município de Bento Gonçalves em face de que os requisitos para o deferimento do pedido se fazem presentes. Primeiro porque o autor demonstrou que o réu foi notificado, pessoalmente, na fl. 13 acerca das irregularidades existentes na obra e, mesmo após o decurso do prazo de dez dias concedida pela administração municipal, não obteve licença e o projeto de reforma não foi autorizado uma vez que se trata de conjunto arquitetônico histórico . Os documentos das fls. 14/16 demonstram a existência da obra e, inclusive a retirada do telhado que se encontra protegido, conforme se depreende das fls. $17 / 23$, em que 0 conjunto arquitetônico se encontra no Inventário do Patrimônio Cultural do Rio Grande do Sul. A responsabilidade de preservação do patrimônio cultural é do Município de Bento Gonçalves conforme determinação constitucional. Transcrevo a lição de José Afonso da Silva, ,in Curso de Direito Constitucional Positivo, 18a Edição, Malheiros Editores, 2000, São Paulo, pág. 819, referente ao patrimônio cultural brasileiro: Define ela o patrimônio cultural brasileiro, como sendo constituído dos bens de natureza material e imaterial, tomados individualmente ou em conjunto, desde que portadores de referência à identidade, á ação, à memória dos diferentes grupos formadores da sociedade brasileira, nos quais se incluem as formas de expressão, os modos de criar, fazer e viver, as criações científicas, artísticas e tecnológicas, as obras, documentos, edificações e demais espaços destinados às manifestações artístico-culturais e os conjuntos urbanos e sítios de valor histórico, paisagístico, artístico, arqueológico, paleontológico, ecológico e científico, patrimônio que deverá ser protegido pelo Poder público, com a colaboração da comunidade, por meio de inventários, registros, , vigilância, tombamento e desapropriação, e de outras formas de acautelamento e preservação. Ou seja, é dever do ente público proceder a fiscalização da preservação do patrimônio, conforme expressamente previsto na CF e CE Art. 23. É competência comum da União, dos Estados, do Distrito Federal e dos Municípios: ... IV - impedir a evasão, a destruição e a descaracterização de obras de arte e de outros bens de valor histórico, artístico ou cultural; Art. 30. Compete aos Municípios: ... IX - promover a proteção do patrimônio histórico-cultural local, observada a legislação e a ação fiscalizadora federal e estadual. Art. 216. Constituem patrimônio cultural brasileiro os bens de natureza material e imaterial, tomados individualmente ou em conjunto, portadores de referência à identidade, à ação, à memória dos diferentes grupos formadores da sociedade brasileira, nos quais se incluem: ........ V - os conjuntos urbanos e sítios de valor histórico, paisagístico, artístico, arqueológico, paleontológico, ecológico e científico. Semelhante disposição encontramos na CE: Art. 221 - Constituem direitos culturais garantidos pelo Estado: ........ V - o acesso ao patrimônio cultural do Estado, entendendo-se como tal o patrimônio natural e os bens de natureza material e imaterial portadores de referências à identidade, à ação e à memória dos diferentes grupos formadores da sociedade rio-grandense, incluindo-se entre esses bens: ... b) os modos de fazer, criar e viver; ... d) as obras, objetos, monumentos naturais e paisagens, documentos, edificações e demais espaços públicos e privados destinados às manifestações políticas, artísticas e culturais; e) os conjuntos urbanos e sítios de valor histórico, paisagístico, artístico, arqueológico, científico e ecológico. ? e) os conjuntos urbanos e sítios de valor histórico, paisagístico, artístico, arqueológico, paleontológico, científico e ecológico. ? NR dada pela Emenda Constitucional no 36, de 12/12/03. Seguindo esta linha de entendimento são as seguintes decisões do Tribunal de Justiça do Estado do Rio Grande do Sul que colaciono: APELA- 
ÇÃO CÍVEL. CONSTITUCIONAL, ADMINISTRATIVO E PROCESSUAL CIVIL. MUNICÍPIO DO RIO GRANDE. AÇÃO CIVIL PÚBLICA. DEFESA DO PATRIMÔNIO HISTÓRICO E CULTURAL. PALACETE TRAJANO LOPES. TOMBAMENTO. SENTENÇA DE PROCEDÊNCIA. MUNICÍPIO. DEVER DE PROTEÇÃO E PRESERVAÇÃO DO SEU PATRIMÔNIO HISTÓRICO, ARTÍSTICO E CULTURAL. COMPETÊNCIA À REALIZAÇÃO DE TOMBAMENTO. RESPONSABILIDADE SOLIDÁRIA DO MUNICÍPIO E DO PROPRIETÁRIO DO PRÉDIO TOMBADO PARA A RECOMPOSIÇÃO E RESTAURO DO QUE JÁ FOI DESTRUÍDO. APELOS IMPROVIDOS. RECURSO ADESIVO PROVIDO. 1. Nos termos da Constituição Federal, art. 23, III, é competência comum da União, do Estado, do Distrito Federal e dos Municípios a proteção de documentos, obras e outros bens de valor histórico, artístico e cultural, os monumentos, as paisagens naturais notáveis e os sítios arqueológicos. No mesmo sentido a previsão da Constituição Estadual (arts. 222 e 223). 2. E tal previsão igualmente consta da Lei Orgânica do Município do Rio Grande (arts. 165 e 166). Outrossim, a Lei municipal n. ${ }^{\circ}$ 5.883/04 dispõe, especificamente, acerca da proteção do patrimônio histórico, artístico e cultural do ente municipal, trazendo capítulo específico sobre o tombamento. 3. Na espécie, trata-se de ação civil pública com pretensão ao tombamento do Palacete Trajano Lopes, no Município do Rio Grande, ante ao seu valor histórico e cultural. 4. E pela legislação referida acima, compete ao Município, pelo meio do tombamento, a proteção e preservação dos seus bens de relevância histórica, artística e cultural, como é o caso do prédio objeto do presente feito. 5. E é solidária a responsabilidade do ente municipal e do proprietário do prédio quanto à recomposição e restauração das partes já destruídas. 6. APELOS IMPROVIDOS. RECURSO ADESIVO PROVIDO. SENTENÇA REFORMADA EM PARTE. (Apelação Cível No 70020498457, Quarta Câmara Cível, Tribunal de Justiça do RS, Relator: Wellington Pacheco Barros, Julgado em 10/10/2007) AÇÃO CIVIL PÚBLICA. PATRIMÔNIO HISTÓRICO,. CONSERVAÇÃO. RESPONSABILIDADE. PROPRIETÁRIO. MUNICÍPIO. Evidenciado nos autos que os proprietários do imóvel tombado demonstraram a impossibilidade de sua conservação junto à Municipalidade, ficando impossibilitados de utilizá-lo pela inércia da administração pública, que tinha dever constitucional de preservá-lo, correta a sentença que condenou o Município de Porto Alegre à conservação permanente do imóvel tombado. Multa diária pelo descumprimento da decisão fixada em R\$500,00. PRIMEIRO APELO DESPROVIDO. SEGUNDA APELAÇÃO PARCIALMENTE PROVIDA. SENTENÇA MANTIDA QUANTO AO MAIS, EM REEXAME NECESSÁRIO. (Apelação Cível No 70021217393, Terceira Câmara Cível, Tribunal de Justiça do RS, Relator: Rogerio Gesta Leal, Julgado em 15/05/2008) APELAÇÃO CÍVEL. ADMINISTRATIVO E PROCESSUAL CIVIL. AÇÃO DE NUNCIAÇÃO DE OBRA NOVA. MUNICÍPIO DE ESTEIO. CONSTRUÇÃO IRREGULAR: SEM PROJETO E SEM LICENÇA. INFRINGÊNCIA AO CÓDIGO DE OBRAS MUNICIPAL (LEI N. ${ }^{\circ}$ 1.261/85). FISCALIZAÇÃO ADMINISTRATIVA. CONSTATAÇÃO DA IRREGULARIDADE. AUTO DE INGRAÇÃO E EMBARGO. CONCESSÃO DE PRAZO PARA REGULARIZAÇÃO. NÃO CUMPRIMENTO. AÇẪO. PROCEDÊNCIA NA ORIGEM. RECURSO A QUE SE NEGA PROVIMENTO. SENTENÇA QUE SE CONFIRMA. 1. Os artigos $1 .^{\circ}$ e 2. ${ }^{\circ}$, do Código de Posturas Municipais (Lei n. ${ }^{\circ} 1.261 / 85$ ), dispõem que qualquer construção, reforma ou ampliação de prédios, no Município, somente poderá ser executada após aprovação do projeto e concessão de licença para execução da obra pelo órgão competente municipal, bem como que os projetos deverão estar de acordo com as disposições da presente lei e legislação vigente sobre o parcelamento do solo e zoneamento de uso. 2. Na espécie, o apelante possuidor da área em que se encontra a edificação, objeto deste feito, deu início a construção irregular que foi embargada pelo Município em fiscalização administrativa, na qual foi constatada ausência de projeto e licença. 3. Concedido prazo para regularização da obra, nada foi feito, advindo, assim, sentença de procedência, cujos fundamentos são de serem mantidos em grau de recurso ante a ausência de elementos a justificar a modificação do decisum a quo, já que atuação do Poder Público, no caso, deu-se para assegurar o cumprimento de uma garantia do interesse geral. 4. APELAÇÃO NÃO PROVIDA. SENTENÇA CONFIRMADA. (Apelação Cível No 70013725817, Quarta Câmara Cível, Tribunal de Justiça do RS, Relator: Wellington Pacheco Barros, Julgado em 31/05/2006) Do exposto, recebo a inicial e defiro o embargo da obra realizada, cessando qualquer ato atinente a continuidade da obra, sob pena de multa diária no valor de um salário mínimo por dia de descumprimento da presente ordem. Cumprida a medida. Defiro o prazo para a juntada da guia Cite-se. Intime-se, inclusive o Ministério Público. DL". 
Assim, celeumas envolvendo a legitimidade de parte, requisito imprescindível ao regular e válido desenvolvimento do processo, inclusive sendo uma das condições da ação, não podem se tornar empecilho à concretização da tutela do meio ambiente. É que dogmas estritamente formais não devem superar um direito fundamental da pessoa, pois inegavelmente este, sem margem a dúvidas, ocupa, nas relações interpessoais com o bem ambiental, posição privilegiada, ainda mais hoje com a preocupação da existência do ambiente ecologicamente equilibrado e servível à vida humana.

A preocupação com a propriedade privada certamente não pode deixar de existir, principalmente em se tratando de garantia do cidadão, mas, por ser garantia, não significa que a mesma se encontre acima de outras garantias também localizadas na estrutura da Lei Fundamental brasileira de 1988.

Com efeito, a harmonia entre a propriedade privada e o bem público ambiental deve permear as relações do homem com o meio ambiente, sempre objetivando a asseguração do patrimônio de todos, ainda mais em se tratando, como já enaltecido, de direito fundamental da pessoa.

Mas ao mesmo tempo em que se possa chocar em conflitos de interesse entre o público e o privado, a tutela ambiental é superior. Isso porque se trata de interesse difuso, que a sua ameaça ou mesmo concretização de dano atinge um número infinitamente grande de indivíduos, ultrapassando o campo da individualidade, sendo, portanto, totalmente indeterminável a quantidade de seres humanos prejudicada pela ação de, pasmem, um único homem, por exemplo.

Conforme ensina Plauto Faraco de Azevedo ${ }^{19}$, não pode a hermenêutica ambiental orientar-se poruma perspectiva individualista. Osprincípiosorientadores do Direito Ambiental exigem a sua ultrapassagem, tanto mais tendo em vista o artigo 225 da Constituição Federal de 1988, e os princípios que a norteiam. Desde a Declaração do Meio Ambiente de Estocolmo, de 1972, evidencia-se à consciência jurídica a emergência do direito à qualidade de vida, novo direito

19 AZEVEDO, Plauto Faraco de. Do Direito Ambiental - Reflexões sobre seu sentido e aplicação. In: Direito Ambiental em Evolução. FREITAS, Vladimir Passos de (Org.). Curitiba: Juruá, 1998. p. 293. 
fundamental da pessoa humana, exigindo, no escólio de José Afonso da Silva ${ }^{20}$, a proteção da natureza em todos os seus elementos essenciais à vida humana e à manutenção do equilíbrio ecológico.

A proteção do meio ambiente, não raras vezes, vai implicar a interferência do público sobre a propriedade privada e, como refere Antonio Herman Benjamin, qualquer tutela do meio implica sempre interferência no direito de propriedade. No mundo contemporâneo, mais e mais os poderosos do direito de propriedade são estatuídos pelas Constituições, leis e jurisprudência de modo bem delimitado. Lamentavelmente, no Brasil, a teoria da função social da propriedade não tem eficácia prática e previsível na realidade dos operadores do direito e no funcionamento do mercado, o que não deveria suceder, considerando-se que poucas constituições unem tão umbilicalmente função social e meio ambiente como a brasileira. No Brasil, não há direito de propriedade que confira a seu titular a opção de usar aquilo que the pertence de modo a violar os princípios estampados nos artigos $5^{\circ}, 170$, VI, 182, § 20, 186 , inciso II, e 225, todos da Constituição Federal. Está claro que, nestas condições, a propriedade privada abandona, de vez, sua configuração essencialmente individualista para ingressar em uma nova fase, mais civilizada e comedida, a qual se submete a uma ordem pública ambiental ${ }^{21}$.

Ao destacar os benefícios da constitucionalização da proteção do meio ambiente, Antonio Herman Benjamin ${ }^{22}$ diz que o primeiro aspecto positivo que se observa nos vários regimes constitucionais do meio ambiente (inclusive o brasileiro) é o estabelecimento de um inequívoco "dever de não degradar', contraposto ao "direito de explorar" inerente ao direito de propriedade clássico, previsto no artigo $5^{\circ}$, inciso, da Constituição Federal de 1988. Trata-se de dever com força vinculante plena e inafastável, não sujeito à discricionariedade estatal ou à livre opção do indivíduo. Sendo de ordem pública, não cabe escolha entre respeitá-lo ou desconsiderá-

20 SILVA, José Afonso da. Direito ambiental constitucional. 4. ed. rev. e atual. São Paulo: Malheiros, 2002. p. 28-44.

21 BENJAMIN, Antonio Herman de Vasconcellos. Reflexões sobre a hipertrofia do direito de propriedade na tutela da reserva legal e das áreas de preservação permanente. Revista de Direito Ambiental. São Paulo: Revista dos Tribunais, v.1, n.4, out./dez. 1996. p. 44; 47; 51-53.

22 BENJAMIN, Antonio Herman de Vasconcellos e. Meio ambiente e constituição: uma primeira abordagem. In: CONGRESSO INTERNACIONAL DE DIREITO AMBIENTAL, 6., 2002, São Paulo. Anais do $6^{\circ}$ Congresso Internacional do Meio Ambiente: 10 anos da Eco-92: o direito e o desenvolvimento sustentável. São Paulo: IMESP, 2002. p. 93. 
lo, abrindo-se, nesta última hipótese, a avenida dos instrumentos reparatórios e sancionatórios, posto à disposição do Estado e das vítimas.

Se antes recorríamos à natureza para dar uma base estável ao Direito (e, no fundo, essa é a razão do Direito Natural), assistimos, hoje, a uma trágica inversão, sendo o homem obrigado a recorrer ao Direito para salvar a natureza que morre ${ }^{23}$.

Entre tantos outros benefícios da constitucionalização, é possível extrair-se da norma reconhecedora da tutela ambiental como valor essencial da sociedade legitimação para agir automática, conferindo aos cidadãos, de modo coletivo, a possibilidade de questionar, administrativa e judicialmente, as hipóteses de ofensa à natureza, à parte de qualquer regulação processual posterior. Isso porque os direitos e as obrigações constitucionais só têm sentido na medida em que podem ser implementados e usados ${ }^{24}$.

Dessa forma, para ser implementada e efetivada na prática a tutela do bem ambiental, deve-se superar dogmas usuais ligados às demandas individuais, analisando-se os casos que envolvem o ambiente de forma diferenciada e voltada à importância constitucional que possui, desgarrando-se de regras descompromissadas com a asseguração desse direito fundamental da pessoa que é o meio ambiente.

\section{CONSIDERAÇÕES FINAIS}

A proteção do patrimônio cultural, no caso brasileiro, resta demonstrada pela evolução da normatização existente no sentido da compreensão de sua função social e de seu papel na sociedade. Mesmo modo, as ferramentas disponibilizadas pelas legislações existentes permitem ao gestor público a efetivação de uma série de restrições em nome da coletividade, determinando que a propriedade seja utilizada de acordo com as diretrizes de crescimento de cada local, todas devidamente explicitadas nos diversos Planos Diretores existentes.

23 REALE, Miguel. Memórias. São Paulo: Saraiva, 1987, p. 129.

24 BENJAMIN, Antonio Herman de Vasconcellos e. Meio ambiente e constituição: uma primeira abordagem. In: CONGRESSO INTERNACIONAL DE DIREITO AMBIENTAL, 6., 2002, São Paulo. Anais do $6^{\circ}$ Congresso Internacional do Meio Ambiente: 10 anos da Eco-92: 0 direito e o desenvolvimento sustentável. São Paulo: IMESP, 2002. p. 95. 
A gama de poder que repousa nas mãos do administrador dele exige uma série de ações no sentido de fazer valer os direitos das maiorias, da sociedade, combatendo as mazelas da pobreza, distribuição de riquezas, reduzindo deficit de habitação e propiciando crescimento e aumento na arrecadação tributária, ao mesmo tempo em que deve garantir e defender o Direito de Propriedade, respeitadas as suas limitações.

Nesse sentido, a atuação escusa ou a omissão do gestor público obriga a intervenção do Poder Judiciário, de maneira que qualquer prática dissimulada deve ser de imediato afastada, já que consideravelmente pesadas as sanções previstas em lei, de certo modo proporcionais ao tamanho do prejuízo ambiental e econômico que as condutas ilícitas podem ocasionar.

Já se perdeu muito tempo com a falta de esmero na proteção ambiental, sendo totalmente contraproducente se perquirir acerca da presença marcante da legitimidade de parte, podendo, na verdade, esta questão, ser superada quando se vislumbrar que o objeto da ação seja tutelar, inequivocamente, o direito fundamental do meio ambiente.

Muito se discute a relação público-privado, especialmente envolvendo duas garantias constitucionalmente asseguradas, quais sejam, o direito à propriedade privada e o direito ao meio ambiente ecologicamente equilibrado.

\section{REFERÊNCIAS}

ADEDE Y CASTRO, João Marcos. Tutela Civil do meio ambiente. Porto Alegre: Sergio Antonio Fabris ED., 2006.

AGUIAR JÚNIOR, Ruy Rosado de. Interpretação. In: REVISTA DA AJURIS. Porto Alegre: Associação dos Juízes do Rio Grande do Sul, n.16 (45), mar. 1989.

AHMED, Flávio; COUTINHO, Ronaldo (Coord.). Cidades Sustentáveis no Brasil e sua Tutela Jurídica. Rio de Janeiro: Editora Lúmen Júris, 2009.

ANTUNES, Paulo de Bessa. Direito Ambiental. 11. ed. Amplamente Reformulada. Rio de Janeiro: Lumen Juris, 2008.

ARAÚJO, Ubiracy. A repartição constitucional de competências em matéria ambiental. In: RIOS, 
Aurélio Virgílio Veiga; INSTITUTO INTERNACIONAL DE EDUCAÇÃO DO BRASIL. 0 direito e o desenvolvimento sustentável: curso de direito ambiental. São Paulo: Petrópolis, 2005.

ARISTOTELES. A Política. Coleção Grandes Obras do Pensamento Universal. Trad.: Nestor Silveira Chaves. São Paulo: Editora Escala. 2003.

AZEVEDO, Plauto Faraco de. Do Direito Ambiental - Reflexões sobre seu sentido e aplicação. In: Direito Ambiental em Evolução. FREITAS, Vladimir Passos de (Org.). Curitiba: Juruá, 1998.

BACHELET, Michel. Ingerência Ecológica: Direito Ambiental em questão. 4. ed. São Paulo: Editora Revista dos Tribunais, 2005.

BARROSO, Luís Roberto. Fundamentos teóricos e filosóficos do novo Direito Constitucional brasileiro (pós-modernidade, teoria crítica e pós-positivismo). Interesse Público, Sapucaia do Sul, RS: Notadez, v.3, n. 11, jul. 2001.

BENJAMIN, Antonio Herman de Vasconcellos e. Meio ambiente e constituição: uma primeira abordagem. In: CONGRESSO INTERNACIONAL DE DIREITO AMBIENTAL, 6., 2002, São Paulo. Anais do $6^{\circ}$ Congresso Internacional do Meio Ambiente: 10 anos da Eco-92: o direito e o desenvolvimento sustentável. São Paulo: IMESP, 2002.

- Reflexões sobre a hipertrofia do direito de propriedade na tutela da reserva legal e das áreas de preservação permanente. Revista de Direito Ambiental. São Paulo: Revista dos Tribunais, v.1, n.4, out./dez. 1996.

BLANCHET, Luiz Alberto. Curso de Direito Administrativo. 2. ed. Curitiba: Juruá, 2000.

CANOTILHO, José Joaquim Gomes. Introdução ao direito do ambiente. Lisboa: Universidade Aberta, 1998.

CHACON, Mario Peña; CRUZ, Ingread Fournier. Derechos Humanos Y Meio Ambiente. In: Revista de Direito Ambiental. São Paulo: Revista dos Tribunais v.10, n.39, jul. 2005.

COUTINHO, Ronaldo. Direito Ambiental das Cidades: Questões Teórico-Metodológicas. In: COUTINHO, Ronaldo; ROCCO, Rogério (Orgs.). Rio de Janeiro: D.P. \& A Editora, 2004.

DERANI, Cristiane. Direito ambiental econômico. 3. ed. São Paulo: Saraiva, 2008.

DUGUIT, León. Las Transformaciones del Derecho (público y privado). Buenos Aires: Editorial Helialista SRL, /s.d./.

GARCIA, Emerson e ALVES, Rogério Pacheco. Improbidade Administrativa. 4. ed. Rio de Janeiro: Ed. Lúmen Júris, 2008. 
GASPARINI, Diógenes. Direito Administrativo. 13. ed. São Paulo: Saraiva, 2008.

HESSE, Konrad. A força normativa da Constituição. Porto Alegre: Sérgio Antônio Fabris Editor, 1991.

MARIN, Jeferson. A constituição desconstituída: antecedentes históricos e o retrato das crises do estado moderno. Revista Científica do Instituto de Pesquisa Cenecista. Bento Gonçalves (RS) : FACEBG. Ano 3, No. 3, Dez/2005.

MENDES, Gilmar Ferreira. Curso de Direito Constitucional. São Paulo: Saraiva, 2007.

MEIRELLES, Hely Lopes. Direito Administrativo Brasileiro. 28. ed. São Paulo: Malheiros Editores, 2003.

MORAES, Alexandre de. Direito Constitucional. 18. ed. São Paulo: Atlas, 2005.

MOREIRA, João Batista Gomes. Poder Judiciário e meio ambiente: um balanço. In: Interesse Público, v.9, n. 45, set./out. 2007. Belo Horizonte: Fórum, 2007.

MOREIRA, José Carlos Barbosa. A proteção jurisdicional dos interesses coletivos ou difusos. In: GRINOVER, Ada Pelegrini (Coord.). A tutela dos interesses difusos. São Paulo: Max Limonad, 1984.

MUKAI, Toshio. Direito urbano-ambiental brasileiro. 2. ed. Rev. e ampl. São Paulo: Ed. Dialética, 2002.

. O Estatuto da Cidade. Anotações à Lei n. 10.257, de 10/07/2001. São Paulo: Ed. Saraiva, 2001.

PORTANOVA, Rui. Princípios do Processo Civil. Porto Alegre: Livraria do Advogado, 1997.

REALE, Miguel. Memórias. São Paulo: Saraiva, 1987, p. 129.

SILVA, Anderson Furlan Freire da. Ativismo judicial em matéria ambiental. p. 58. In: Direito Ambiental em Evolução. FREITAS, Vladimir Passos de (Coord.). n. 3, Curitiba: Juruá, 2002.

SILVA, Jaqueline Mielke. $\mathbf{O}$ direito processual civil como instrumento de realização de direitos. Porto Alegre: Verbo Jurídico, 2005.

SILVA, José Afonso da. Direito ambiental constitucional. 4. ed. rev. e atual. São Paulo: Malheiros, 2002, p. 28

Recebido em: jun/2014

Aprovado em: set/2014 